\title{
"Só de pensar em vir trabalhar, já fico de mau humor": atividade de atendimento ao público e prazer-sofrimento no trabalho ${ }^{1}$
}

\author{
Mário César Ferreira \\ Ana Magnólia Mendes \\ Universidade de Brasília
}

\begin{abstract}
Resumo
O texto aborda a inter-relação entre atividade de atendimento ao público e vivências de prazer-sofrimento no trabalho. A perspectiva de investigação é interdisciplinar, a partir de um diálogo entre a ergonomia francófona e a psicodinâmica. Em ergonomia, são utilizadas as noções de serviço de atendimento ao público, atividade e carga de trabalho, enquanto que em psicodinâmica são utilizados conceitos que fundamentam o prazer-sofrimento no trabalho. A pesquisa realizou-se em uma instituição pública do Distrito Federal com 64 sujeitos. A metodologia articula técnicas de coleta e análise de dados qualitativa e quantitativa, utilizando Análise Ergonômica do Trabalho - AET e a Escala de Prazer-Sofrimento no Trabalho - EPST. Os resultados mostram que a atividade de trabalho constitui um dos elementos explicativos para a predominância de vivências de sofrimento dos atendentes. Trata-se de um estudo exploratório que avança na interface entre as duas disciplinas, estabelecendo algumas perspectivas para novos estudos.
\end{abstract}

Palavras-chave: Ergonomia, Psicodinâmica, Atividade, Atendimento ao público, Prazer-sofrimento.

\begin{abstract}
"When I think of coming to work, I get into a bad mood": Public attendance and pleasure-suffering at the workplace

The paper approaches the interrelation between public costumer service activity and pleasure-suffering existences at work. Interdisciplinary perspective is used in this investigation, through a dialogue between Francophonic ergonomics and psychodynamics. Categories as public costumer service, activity, work load support ergonomic theoretical reference and pleasure-suffering psychodynamic. The research took place at a public institution of Distrito Federal with 64 subjects. The methodology articulates qualitative and quantitative techniques to collect and analize data, using Ergonomic Analysis at Work and the Pleasure-suffering at Work Scale. The results demonstrate that work activity constitutes one of explanatory elements for predominance of suffering of costumer service attendants. It is a exploratory study that seeks the interface between two disciplines, establishing some perspectives for new studies.

Key words: Ergonomics, Public customer service, Activity, Pleasure and suffering.
\end{abstract}

$\mathrm{O}$ objetivo desse texto é abordar a inter-relação entre a atividade de trabalho e as vivências de prazer-sofrimento dos trabalhadores em um contexto organizacional específico de atendimento ao público, buscando identificar seu impacto no bem-estar psíquico dos sujeitos. A partir de um estudo de caso, a abordagem da temática é construída com base em um diálogo teóricometodológico entre duas disciplinas: a ergonomia francófona e a psicodinâmica do trabalho.
A relação entre essas duas disciplinas tem sido amplamente discutida. $O$ ponto de intersecção entre elas encontrase na preocupação de estudar o contexto de trabalho como um fator que influencia a saúde do trabalhador. Ambas distinguem-se nas especificidades do seu objeto de estudo e na metodologia para apreendê-lo, o que não invalida a tentativa de buscar relações que ampliem e complementem o entendimento da inter-relação entre bem-estar psíquico de determinada categoria profissional e suas atividades de trabalho. 
O enfoque teórico adotado para investigar a inter-relação fundamenta-se em duas premissas interdependentes: a atividade do sujeito em situação de trabalho é um processo permanente de regulação que visa responder adequadamente aos objetivos das tarefas, às múltiplas determinações do contexto de trabalho (situacionais, físicas, materiais, instrumentais, organizacionais, sociais), e à avaliação que o sujeito faz de seu estado interno; e o prazer-sofrimento é uma vivência subjetiva do próprio trabalhador, compartilhada coletivamente e influenciada pela atividade de trabalho. Nessa perspectiva analítica, todo o trabalho veicula implicitamente um custo humano que se expressa sob a forma de carga de trabalho, e as vivências de prazer-sofrimento têm como um dos resultantes o confronto do sujeito com essa carga que, por conseguinte, impacta no seu bem-estar psíquico.

A importância desse estudo prende-se, principalmente, aos seguintes aspectos: o serviço de atendimento ao público é, ainda, um campo de investigação pouco conhecido nas ciências humanas; a abordagem centra-se na interface da ergonomia com a psicodinâmica, cujas pesquisas têm sido conduzidas de forma isolada; e os resultados obtidos podem contribuir para estabelecer novas linhas de investigação e aprimorar o instrumental teórico-metodológico utilizado. Do ponto de vista organizacional, as recomendações formuladas com base nos resultados obtidos podem contribuir para garantir o bem-estar dos sujeitos, a eficiência e a eficácia dos serviços prestados.

O enfoque metodológico para a análise do recorte temático - centrado na atividade de atendimento e nas vivências de prazer-sofrimento no trabalho - orientou-se pelas seguintes questões: em que consistem as atividades de atendimento ao público no contexto organizacional estudado ? Quais são as condições de trabalho, disponibilizadas pela instituição, que caracterizam o serviço de atendimento e influenciam a atividade dos sujeitos? Como os atendentes percebem o trabalho que realizam ? Como se caracterizam suas vivências de prazer-sofrimento ?

A busca de respostas para essas questões guiou-se pela construção de um quadro teórico específico de referência, articulando conhecimentos oriundos da ergonomia e da psicodinâmica para entender o mesmo objeto de investigação.

\section{Quadro teórico de referência}

O contexto de serviço de atendimento ao público constitui o cenário sociotécnico do trabalho no qual se inscreve a atividade dos sujeitos. Esse cenário é um objeto de investigação relativamente recente em ergonomia (Falzon \& Lapeyrière, 1998; Santos, Chaves, Pavão \& Bijos, 1994). O esforço de elaboração conceitual do fenômeno atendimento ao público, buscando caracterizar esse tipo de situação de trabalho, deu origem ao primeiro esboço teórico-metodológi- co que tem orientado alguns estudos (Ferreira, Araujo \& Araujo, 1998; Gonçalves \& Ferreira, 1999).

Nessa abordagem, o atendimento ao público constitui, freqüentemente, um serviço terminal que resulta da sinergia de multivariáveis: a conduta do usuário, as atividades dos funcionários envolvidos na situação, a organização do trabalho e as condições físico-ambientais/instrumentais. Assim, o atendimento ao público pode ser definido como um serviço complexo que coloca em cena diferentes interlocutores, cuja interação social é mediada por distintas necessidades, podendo ser facilitada ou dificultada em função das condições (físicas, materiais, instrumentais, organizacionais) disponibilizadas pela organização. Em ergonomia, o estudo da temática é centrado nas situações nas quais se desenrola o serviço (setting organizacional) e emergem os indicadores críticos como, por exemplo, tempo excessivo de espera e reclamações dos usuários (Ferreira, Carvalho \& Sarmet, 1999; Freire \& Ferreira, 2000).

Os disfuncionamentos existentes constituem a ponta do iceberg, buscando-se investigar sua gênese a partir de uma perspectiva tridimensional: (a) a lógica da instituição, identificando os fatores (processos organizacionais e suportes disponibilizados) que caracterizam o modo de ser habitual da instituição; (b) a lógica do atendente, analisando os fatores (perfil individual, competência profissional e estado de saúde) que caracterizam o modo operatório usual do funcionário, estruturadores da conduta nas situações de atendimento; (c) a lógica do usuário, analisando os fatores (perfil socioeconômico e representação social) que caracterizam o modo de utilização dos serviços pelos usuários e seu comportamento nas situações de atendimento. Nessa abordagem, a atividade do sujeito é uma categoria nuclear de análise.

Segundo os enfoques e campos de interesse, o conceito de atividade varia, evidenciando o seu caráter nômade e polissêmico (Ferreira, no prelo; Hubault, 1995). Todavia, observa-se que a variabilidade de aspectos evocados na literatura caracteriza-se, sobretudo, pela ênfase em aspectos que se complementam mutuamente, oriundos de disciplinas com as quais a ergonomia vem estabelecendo um diálogo: Psicologia, Sociologia, Filosofia (Schwartz, 1992; Teiger, 1992; Terssac, 1995). Em ergonomia, a atividade constitui uma categoria teórica central que orienta o "olhar" dos ergonomistas no estudo do trabalho (Leplat \& Hoc, 1983). A noção de atividade não tem vocação para abstração, ao contrário, ela aparece inseparável, lato sensu, de um corpo, de uma temporalidade e de um contexto sociotécnico.

Assim, para a ergonomia o trabalho é uma atividade mediadora entre o sujeito e um contexto singular que se caracteriza como uma via de mão dupla: o sujeito, ao agir direta ou indiretamente (mediação instrumental) sobre o meio pela atividade de trabalho, é, ao mesmo tempo, transforma- 
do por ele em função dos efeitos e resultados de sua ação. Tal interação não se opera ao acaso, mas é guiada por objetivos que o sujeito coloca para si em função das propriedades da situação e de seu objeto de ação (finalismo). A estruturação dos objetivos orienta a interação com o meio e resulta de um processo de apropriação (no sentido piagetiano do termo) e de releitura do que foi prescrito pela organização do trabalho.

Essa interação, mediada pela atividade, é abordada em termos de estratégias de regulação e compensação do sujeito, e resultam do acúmulo de suas experiências e do conhecimento do seu próprio funcionamento (Weill-Fassina, 1990; Weill-Fassina, Dubois \& Rabardel, 1993). Tais estratégias se expressam por meio de modos operatórios que o sujeito constrói (de forma mais ou menos consciente), buscando estabelecer um compromisso (não-estável) de compatibilidade entre os objetivos da produção, a competência que ele dispõe e a preservação de sua saúde (Laville, 1983; Wisner, 1994).

Nessa perspectiva, a produção teórica em ergonomia opera uma distinção importante entre os conceitos de atividade e tarefa. O conceito de tarefa expressa o trabalho prescrito que estabelece, principalmente, o que e o como do trabalho a ser executado (Laville, Teiger \& Daniellou, 1989), dando visibilidade aos "braços invisíveis" da organização do trabalho, cuja pretensão é, em certa medida, fixar os "trilhos da atividade".

Para a ergonomia, a discrepância existente entre a tarefa prescrita e a atividade dos sujeitos constitui uma dimensão crucial a ser explorada, buscando-se identificar, principalmente, o custo humano do trabalho. Tal custo é abordado em termos de carga de trabalho (Brito, 1991; Ferreira \& Marcelin, 1983; Moraes \& Mont'Alvão, 1998), cujos componentes - físico, cognitivo e psíquico - que lhe são inerentes, exigem do sujeito um esforço permanente de adaptação e evidenciam a função mediadora da inter-relação trabalhodesgaste vivenciada por ele (Daniellou, 1984; Laurell \& Noriega, 1989; Leplat, 1996).

A atividade expressa uma modalidade de comportamento do sujeito que tende a ser estruturada sob a forma de estratégias e modos operatórios para responder às exigências físicas, cognitivas e psíquicas inerentes às tarefas e às condições de trabalho disponilizadas pela organização. Do ponto de vista social, o trabalho envolve diferentes sujeitos em interação com determinada realidade, dando lugar à produção de significações psíquicas e de (re)construção de relações sociais. Por esta razão, as influências deste contexto podem ser multideterminadas (positivas ou negativas), dependendo do confronto entre o sujeito e a atividade, relação essa definidora da qualidade do bem-estar psíquico do trabalhador.

Assim, a forma como o trabalho é realizado permite a percepção da atividade como significativa ou não, influenciando o sentido particular que ela assume para cada sujeito, sendo a partir da construção deste sentido específico que emergem vivências de prazer e de sofrimento.

O prazer-sofrimento no trabalho tem sido estudado pela psicodinâmica do trabalho desde os anos 80 , como um constructo dialético. Pesquisas realizadas por Mendes (1995, 1999), Mendes e Linhares (1996) e Mendes e Abrahão (1996) indicam que o prazer é vivenciado quando o trabalho favorece a valorização e reconhecimento, especialmente, pela realização de uma tarefa significativa e importante para a organização e a sociedade. O uso da criatividade e a possibilidade de expressar uma marca pessoal também são fontes de prazer e, ainda, o orgulho e admiração pelo que se faz, aliados ao reconhecimento da chefia e dos colegas.

As vivências de sofrimento aparecem associadas à divisão e à padronização de tarefas com subutilização do potencial técnico e da criatividade; rigidez hierárquica, com excesso de procedimentos burocráticos, ingerências políticas, centralização de informações, falta de participação nas decisões e não-reconhecimento; pouca perspectiva de crescimento profissional.

Segundo Dejours (1987, 1993, 1994), o trabalho contém vários elementos que influenciam a formação da autoimagem do trabalhador que, por sua vez, é razão para o sofrimento. Tais pesquisas revelam que situações de medo e de tédio são responsáveis pela emergência do sofrimento, que se reflete em sintomas como a ansiedade e a insatisfação. Apontam ainda para a relação entre esses sintomas e a incoerência entre o conteúdo da tarefa e as aspirações dos trabalhadores; a desestruturação das relações psicoafetivas com os colegas; a despersonalização com relação ao produto; frustrações e adormecimento intelectual. Ainda em relação ao sofrimento, pesquisas realizadas por Jayet (1994) resultam em categorias de signos indicadores do sofrimento associado ao trabalho (Tabela 1).

Para Dejours (1995, 1997, 1998), o sofrimento, além de ter origem na mecanização e robotização das tarefas, nas pressões e imposições da organização do trabalho, na adaptação à cultura ou ideologia organizacional, representada nas pressões do mercado, nas relações com os clientes e com o público, é também causado pela criação das incompetências, significando que o trabalhador se sente incapaz de fazer face às situações convencionais, inabituais ou erradas, quando acontece a retenção da informação que destrói a cooperação.

Ainda para o autor, as novas formas de sofrimento estão associadas às atuais formas de organização do trabalho. Os itens mais relevantes nessas mudanças são a cooperação e a reprovação. $O$ trabalhador tem de fazer o que não fazia antes, e esta diferença pode implicar reprovação, que não passa pela questão moral ou social, ou de culpa do superego, mas é uma traição ao próprio eu, um risco de perder a iden- 
Tabela 1.

Indicadores de Sofrimento no Trabalho, segundo Jayet (1994)

- Medo físico relacionado à fragilidade do corpo quando exposto a determinadas condições de trabalho.

- Medo moral, que significa o medo do julgamento dos outros e de não suportar a situação de pressão e adversidade na qual realiza a tarefa.

- Tédio por desempenhar tarefas pouco valorizadas.

- Sobrecarga do trabalho, gerando a impressão de que não vai dar conta das responsabilidades.

- Ininteligibilidade das decisões organizacionais, que gera falta de referência da realidade.

- Ambivalência entre segurança, rentabilidade e qualidade.

- Conflitos entre valores individuais e organizacionais.

- Incertezas sobre o futuro da organização e seu próprio futuro.

- Perda do sentido do trabalho a partir da não-compreensão da lógica das decisões, levando à desprofissionalização.
- Dúvidas sobre a utilidade social e profissional do seu trabalho.

- Sentimento de injustiça, reflexo da ingratidão da empresa e das recompensas sem considerar as competências.

- Falta de reconhecimento retratada na ausência de retribuição financeira ou moral e do não-reconhecimento do mérito pessoal.

- Dificuldade de poder dar sua contribuição à sociedade, gerando um sentimento de inatividade, de inutilidade e de depreciação da sua identidade profissional.

- Falta de confiança, que produz a negação dos problemas, manifestada em um sentimento de desordem, de culpabilidade, de vergonha e de fatalidade para lidar com as situações de trabalho. tidade, a promessa que fez a si mesmo, e que não pode ser resgatada, gerando uma "ferida" na sua cidadania.

Dessa forma, o sofrimento é capaz de desestabilizar a identidade e a personalidade, conduzindo a problemas mentais; mas ao mesmo tempo, é elemento para a normalidade, quando existe um compromisso entre o sofrimento e a luta individual e coletiva contra ele, sendo o saudável não uma adaptação, mas o enfrentamento das imposições e pressões do trabalho que causam a desestabilidade psicológica, tendo lugar o prazer quando esse sofrimento pode ser transformado.

A partir destas pesquisas, Mendes (1999) elaborou um conceito a partir de dados empíricos para as vivências de prazer-sofrimento, o qual fundamenta a abordagem da psicodinâmica neste estudo. Esse conceito é uma operacionalização do constructo que deu origem à elaboração de uma escala submetida à análise fatorial, resultando em três indicadores de cada uma das vivências.

Nesse estudo, o prazer é definido a partir de dois fatores: valorização e reconhecimento no trabalho. A valorização é o sentimento de que o trabalho tem sentido e valor em si mesmo, é importante e significativo para a organização e a sociedade. O sentimento de reconhecimento significa ser aceito e admirado no trabalho e ter liberdade para expressar sua individualidade. O sofrimento é definido a partir do fator desgaste, que é a sensação de cansaço, desânimo e descontentamento com relação ao trabalho.

Verifica-se, então, que a discrepância entre tarefa prescrita e atividade real, enquanto desencadeadora de um custo psíquico para o trabalhador, traz consequências para a organização do trabalho em termos da natureza da tarefa em si e das relações socioprofissionais, fazendo com que o sujeito se coloque em estado de esforço permanente para dar conta da realidade, muitas vezes, incompatível com seus investimentos psicológicos e seus limites pessoais, gerando sofrimento. Quando existe uma predominância da compatibilidade entre tarefa prescrita e atividade real, ou uma flexibilidade na organização do trabalho que permita a negociação ou ajustamento do sujeito às condições adversas da situação, têm lugar vivências de prazer.

Nesse sentido, a ergonomia e a psicodinâmica do trabalho contribuem para uma análise do contexto de trabalho à medida que envolvem aspectos concretos das situações e aspectos simbólicos representativos dessa realidade para os indivíduos; isso revela a importância que a atividade assu- 
me para o sujeito, desencadeando vivências de prazer e de sofrimento no trabalho.

\section{Abordagem Metodológica}

\section{Contexto sociotécnico do trabalho de atendimen- to ao público}

A instituição pesquisada vincula-se à Secretaria de Segurança Pública. Ela é de uma entidade autárquica de administração superior, integrante do Sistema Nacional de Trânsito, cujas finalidades principais são registro e licenciamento de veículos; formação, habilitação e reciclagem de condutores; policiamento e fiscalização de trânsito; aplicação de penalidades. Trata-se de uma instituição, no rol das públicas, com maior flexibilidade para gerir sua estrutura administrativa e de pessoal em função da autonomia que lhe é garantida juridicamente.

Para operacionalizar suas finalidades, a instituição tem como uma de suas fontes de recursos financeiros o recolhimentos de taxas pelos serviços prestados aos usuários. Isto constitui um fator importante para a compreensão da relação instituição-público, pois agrega um componente - usuário mais exigente - que influencia as interações sociais estabelecidas no contexto do serviço de atendimento.

A instituição dispõe de uma estrutura administrativa ascendente vertical, cuja "ossatura" está baseada na existência de diretorias, divisões, seções e núcleos. Os dados foram coletados nas seções de Cadastro e Habilitação de Condutores, Registro e Licenciamento de Veículos, Serviço de Controle de Infrações, Serviço de Processamento de Dados e no guichê de Recepção e Informações, unidades organizacionais escolhidas em função do papel estratégico no contato direto com o público.

Apesar do funcionamento ainda precário do Núcleo de Pesquisa e Processamentos de Dados, alguns elementos servem como indicadores do volume de serviços prestados pela instituição, relacionados direta ou indiretamente com o público: a frota de veículos em 1999 foi estimada em 800 mil unidades; o fluxo mensal de público na sede é de aproximadamente 16 mil usuários; a seção de licenciamento de veículos tem a maior demanda, com cerca de 550 usuários/dia.

\section{Participantes}

A pesquisa realizou-se com uma amostra de 64 participantes de um total de 82 funcionários lotados no serviço de atendimento da instituição. A amostra caracteriza-se, predominantemente, por funcionários exercendo os cargos de técnico em informática, pesquisador de veículos e assistente de trânsito, lotados na Seção de Licenciamento de Veículos e na Seção de Habilitação, com escolaridade de $2^{2}$ grau completo, sexo feminino, casados e com tempo de serviço entre um e cinco anos.

\section{Instrumentos}

Para investigar a atividade, realizaram-se as observações livre e sistemática e entrevistas individuais. Para medir as vivências de prazer-sofrimento, utilizou-se a "Escala de Prazer-sofrimento no Trabalho - EPST", validada por Mendes (1996).

\section{Procedimentos}

A EPST foi aplicada individualmente em todos os funcionários do serviço de atendimento, no total de 82, dos quais apenas 64 instrumentos foram devolvidos. Sua utilização objetivou traçar um quadro epidemiológico da situação atual dos funcionários em relação ao seu bem-estar psíquico. Vale ressaltar que a proposta da escala é oferecer indicadores a partir da investigação dos fatores que compõem as vivências de prazer-sofrimento no trabalho.

As observações livres realizaram-se em dez postos de trabalho com o objetivo de manter os primeiros contatos com os funcionários e estabelecer uma visão panorâmica do trabalho e das condições em que é realizado. Elas tiveram a duração de 16 horas e foram registradas a partir de anotações escritas e uso de gravações em fitas cassetes.

As observações sistemáticas ocorreram em seis postos de trabalho com os objetivos de: (a) identificar e colocar em contexto os modos operatórios dos sujeitos em função das exigências e da evolução das situações; (b) registrar e quantificar categorias de análise em intervalos de tempo prédefinidos no curso da atividade dos sujeitos. O tempo destinado à etapa foi de seis horas e para registrá-la contou-se com o suporte de câmera VHS e máquina fotográfica.

As entrevistas individuais semi-estruturadas foram realizadas com 31 funcionários da amostra pesquisada e tiveram por objetivo: (a) identificar estratégias cognitivas de trabalho dos sujeitos; (b) validar os dados coletados, sobretudo, os oriundos da observação sistemática. Elas tiveram uma duração média de 40 minutos e seu registro se deu por meio de anotações manuais.

Quanto à análise dos dados, as observações e as entrevistas foram descritas qualitativamente com base na análise de conteúdo categorial (Bardin, 1974) referentes à atividade de atendimento e às condições de trabalho. Analisou-se a EPST em termos de técnicas de estatística descritiva, média, desvio-padrão e teste " $t$ " de diferença das médias. Os dados obtidos foram sistematizados sob a forma de quadros, tabelas e figuras.

Os resultados de cada um dos instrumentos são integrados na discussão do trabalho e formam um conjunto de dados que, apesar de abordados metodologicamente de maneira distinta, fornecem subsídios para o estabelecimento de relações, tanto do ponto de vista empírico quanto teórico, no sentido de atender aos objetivos do estudo. 


\section{Resultados e discussão}

A análise da atividade de atendimento nos setores observados possibilitou construir um cenário explicativo da interrelação dos sujeitos com o trabalho, identificando e avaliando diferentes fatores que caracterizam as exigências externas e fornecem elementos para a compreensão dos resultados obtidos nas vivências de prazer e sofrimento no trabalho.

A atividade de atendimento ao público: um ritual quotidiano de tratamento de informações

Globalmente, o quotidiano dos atendentes é marcado por três momentos distintos: (a) organização e preparação do posto de trabalho para o início da jornada; (b) o atendimento das múltiplas demandas dos usuários, durante o expediente ao público; e (c) encaminhamento e arquivamento de documentos resultantes dessas demandas. Logo, o atendimento ao público constitui o centro das atividades dos funcionários e sua variabilidade é determinada pelo universo de tarefas prescritas. O serviço transferência de veículos (Figura 1), realizado com alta freqüência no Setor de Licenciamento de Veículos, é representativo das modalidades de procedimentos típicos no trabalho dos atendentes.

A análise de diferentes fluxos dos procedimentos de rotina possibilitou evidenciar um traço característico do trabalho de atendimento ao público: é uma atividade rotineira complexa de tratamento de informações, marcada por pro- cedimentos administrativos habituais, estruturados em uma lógica algorítimica do tipo "Se... (tal situação ou evento se apresenta), então... (executa-se tal procedimento)". Como no exemplo apresentado na Figura 1, se o usuário deseja transferir a propriedade de seu veículo (diagnóstico), então é imperioso (tomada de decisão) verificar se ele apresenta a documentação exigida.

Assim, o tratamento de informações é baseado predominantemente no diagnóstico das exigências da situação, com base em critérios prescritos pela instituição, que orienta as tomadas de decisão. A atividade de atendimento implica um conjunto de ações rotineiras, principalmente, de solicitação, identificação, cotejamento, pesquisa, registro, emissão, orientação e arquivamento de informações.

\section{Condições de trabalho que influenciam as atividades dos atendentes}

A análise ergonômica possibilitou levantar os principais fatores que caraterizam as condições de trabalho dos atendentes. Globalmente, eles expressam a dimensão material e instrumental do trabalho e funcionam como elementos estruturadores das estratégias operatórias dos sujeitos para responder às exigências do trabalho prescrito. Dentre os principais aspectos críticos constatados, merecem destaque: a sinalização interna, o layout do local de atendimento, os postos de trabalho existentes e o sistema informatizado.

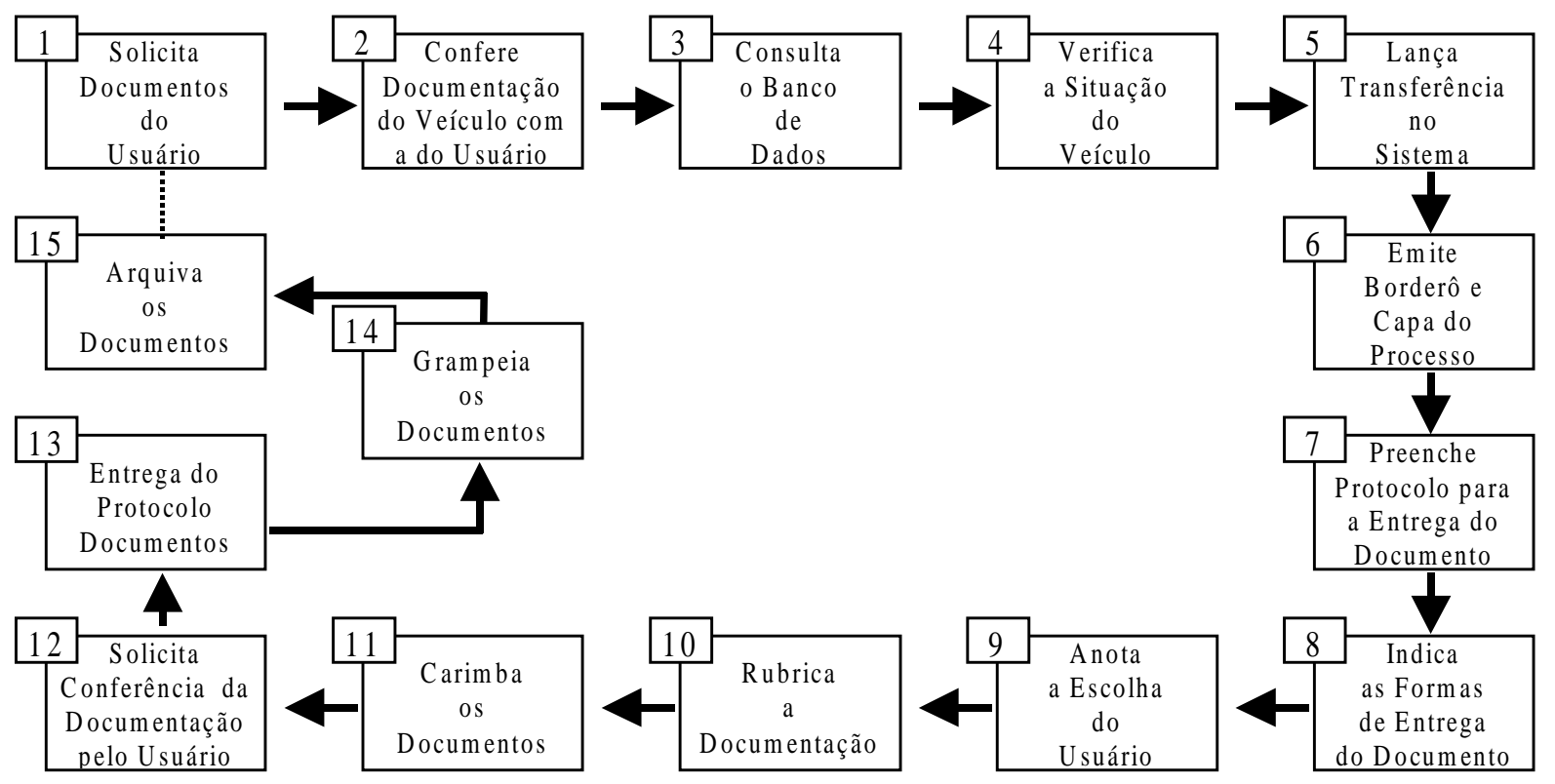

Figura 1. Fluxo dos procedimentos de rotina dos atendentes no Serviço de Transferência de Veículos (Setor de Licenciamento de Veículos - SELIVE). 
A sinalização interna do espaço da insituição é praticamente inexistente. Constatou-se enorme perturbação visual, composta por resquícios de uma sinalização que se expressa, principalmente, sob a forma de papéis impressos e manuscritos, placas de papelão e dizeres em vinil colados nos vidros. Regra geral, os elementos de sinalização encontramse dispostos de forma inadequada, dificultando a percepção e a orientação dos usuários. Como consequiências principais, observam-se os seguintes problemas:

(a) deficiência estética, pois não se utilizam criteriosamente padrões cromáticos, tipográficos e signos lingüísticos;

(b) falta de padronização dos meios de sinalização em função da diversidade de veículos de informação utilizados;

(c) inexistência de sinalização em locais estratégicos, caso da porta de entrada do local de atendimento;

(d) incompatibilidade com as normas de segurança, pois não há sinalização indicando saídas de emergência e extintores.

Em síntese, a improvisação constitui a principal característica no trato institucional da sinalização, produzindo impactos negativos para o serviço de atendimento ao público: contribuindo para a interrupção do trabalho, potencializando a ocorrência de erros, retrabalho e incidentes; aumentando o nível de ruído proveniente das conversas entre usuários, dificultando a concentração dos atendentes; e, principalmente, aumentando o esforço dos usuários no processo de busca de informações e orientação; assim, os recursos de sinalização visual geram incertezas nas pessoas, obrigando-as, por exemplo, comumente a entrar na fila para obter, muitas vezes, uma informação banal.

O layout do local de atendimento constitui outro fator crítico, pois a distribuição da estrutura organizacional e as modalidades de utilização do espaço físico não atendem aos aspectos sociotécnicos dos serviços e às necessidades dos sujeitos. Dentre os principais problemas existentes, destacam-se:

(a) distribuição espacial da estrutura organizacional inadequada às rotinas e aos procedimentos dos serviços, dificultando a circulação de usuários e o fluxo de funcionários;

(b) co-habitação de setores de back-office e front-office no local de atendimento, indicando uma disposisão nãocriteriosa de unidades organizacionais;

(c) localização inapropriada do guichê de recepção e informação, dificultando sua identificação pelos usuários;

(d) espaço físico insuficiente e desconfortável para os usuários no local de espera, obrigando-os, em muitos casos, a esperar em pé para serem atendidos;

(e) arranjamento espacial dos guichês de atendimento que não atenta à diversidade, à variabilidade e às especificidades dos usuários (por exemplo, atendimento diferenciado para gestantes, idosos e deficientes físicos).
Tais limites de layout do local de atendimento reduzem a qualidade dos serviços prestados pela instituição e repercutem negativamente nas situações de atendimento ao público, pois tendem a transformar o usuário em um "barril de pólvora" prestes a explodir no guichê, contribuindo, dessa forma, para agravar o seu relacionamento com os atendentes.

Os postos de trabalho, disponibilizados pela organização para o atendimento ao público, colocam limites aos atendentes para a execução eficiente dos serviços e uma interação eficaz com os usuários. O mobiliário utilizado, regra geral, é antigo - sua aquisição data de 1982 - e não acompanhou a evolução dos serviços e o crescimento das demandas.

Os limites constatados são determinados, sobretudo, pela formatação (arranjamento) e pelas dimensões de seus componentes (Figura 2), produzindo: (a) a perda da qualidade estética em função do uso inadequado ou não-criterioso de formas, cores, texturas, tipos de materiais; (b) a redução da qualidade funcional pela evolução das necessidades de funcionários e usuários, constituindo-se em obstáculos para a eficácia dos serviços prestados pela instituição; (c) a redução da qualidade ergonômica diante dos limites impostos às atividades dos sujeitos, dificultando a eficiência na execução dos serviços (manuseio, compatibilidade de movimentos, segurança e conforto) e o bem-estar dos funcionários.

A análise de interface do sistema informatizado, à época do estudo em fase de reconversão, evidenciou um conjunto de limites do software do serviço de atendimento ao público, sob duas dimensões complementares:

(a) limites intrínsecos: em algumas telas, as funções de alterações, multas, consultas e impressões não estão agru-

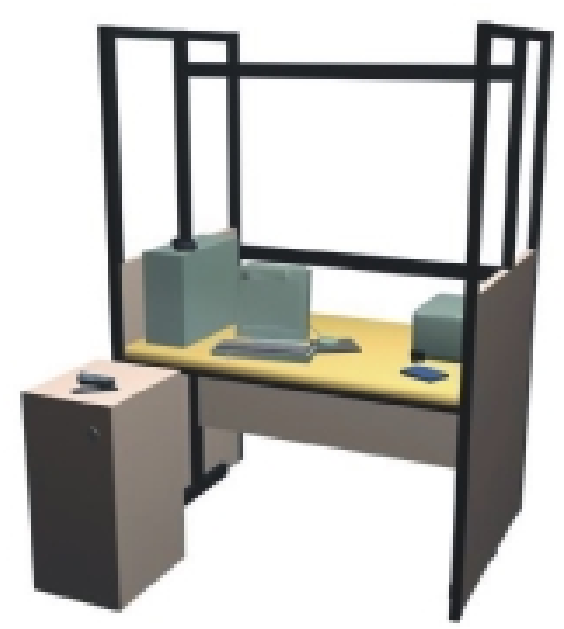

Figura 2. Posto de trabalho típico utilizado no atendimento ao público 
padas espacialmente, dificultando a memorização e discriminação dos diferentes ícones pelos atendentes; a lógica de funcionamento do sistema impõe ao atendente a necessidade de voltar às telas iniciais toda vez que este precisa mudar de uma função para outra, aumentando a carga de trabalho e potencializando a probabilidade de erros e retrabalho; algumas telas iniciais possuem funções que são utilizadas raramente, aumentando a densidade informacional;

(b) limites extrínsecos: a lógica de funcionamento do programa concebida para a modificação de dados do usuário requer o refazer de etapas, levando ao retrabalho; a lógica de navegação impõe, em muitos casos, que os funcionários cliquem até cinco vezes consecutivas no ícone com o objetivo de retornar, passo a passo, à tela inicial; as duas funções mais utilizadas (consulta e impressão de borderô) se encontram em páginas diferentes do menu, exigindo que o funcionário mude sempre de uma tela para outra, em todos os serviços realizados; algumas funções no sistema possuem uma frequiência de utilização quase nula, com relatos de total desinformação sobre sua utilidade; as mensagens de erro em inglês geram dificuldades de interpretação pelos funcionários que não conhecem o idioma.

Os resultados evidenciam a vocação tecnocêntrica no uso da informática, ou seja, vários aspectos de seu funciona- mento mostram uma concepção que não atende de modo satisfatório à lógica de trabalho dos atendentes, gerando um conflito de interação entre os funcionários e o sistema informatizado que impacta negativamente na qualidade da interação com o usuário. Os conflitos de interação na interface aumentam, sobretudo, o custo cognitivo do trabalho (exemplo, quantidade de etapas para navegar no software), levando os atendentes a construir estratégias para amenizar as suas conseqüências.

\section{As múltiplas exigências da atividade de atendimento ao público: indicadores da complexidade do trabalho}

O tratamento de informações que caracteriza a natureza da atividade dos atendentes assume uma feição singular no contexto sociotécnico estudado em função de múltiplas exigências externas, oriundas das condições e das relações sociais de trabalho existentes. Tais exigências são reveladoras da carga cognitiva de trabalho singular dos atendentes, e dão visibilidade aos indicadores da complexidade do trabalho dos funcionários no setting organizacional do atendimento (Tabela 2).

Do ponto de vista psicológico, tais indicadores de complexidade impõem aos atendentes exigências cognitivas (perceptivas, mnemônicas, elaboração mental) em um con-

Tabela 2.

Indicadores de Complexidade na Atividade de Atendimento ao Público

\begin{tabular}{|c|c|c|}
\hline Indicadores & $\begin{array}{l}\text { Aspectos críticos influenciando a } \\
\text { atividade de atendimento }\end{array}$ & $\begin{array}{l}\text { Segmentos ilustrativos das } \\
\text { verbalizações dos atendentes }\end{array}$ \\
\hline $\begin{array}{c}\text { Dinâmica } \\
\text { da Situação }\end{array}$ & $\begin{array}{ll}\text { - } & \text { Mudanças organizacionais } \\
\text { - } & \text { Introdução de novos equipamentos } \\
\text { - } & \text { Fluxo sazonal dos usuários }\end{array}$ & $\begin{array}{c}\text { "Nós aqui somos os últimos a saber do que está } \\
\text { acontecendo. A gente precisa ter mais } \\
\text { informações com relação aos procedimentos do } \\
\text { setor." }\end{array}$ \\
\hline $\begin{array}{l}\text { Quantidade } \\
\text { de } \\
\text { Informações }\end{array}$ & $\begin{array}{ll}\text { - } & \text { Registro de dados dos usuários } \\
\text { - } & \text { Prescrição técnico-administrativa } \\
\text { - } & \text { Modalidades de tarefas }\end{array}$ & $\begin{array}{l}\text { "Chega um momento que eu não quero } \\
\text { mais falar, fico muito cansada". }\end{array}$ \\
\hline $\begin{array}{l}\text { Variabilidade } \\
\quad \text { dos } \\
\text { Informações }\end{array}$ & $\begin{array}{ll}\text { - } & \text { Especificidades das demandas } \\
\text { - } & \text { Diversidade de tarefas } \\
\text { - } & \text { Instruções normativas }\end{array}$ & $\begin{array}{l}\text { "Muitas vezes o usuário vem aqui } \\
\text { resolver um problema que não é aqui." }\end{array}$ \\
\hline $\begin{array}{l}\text { Interações } \\
\text { Sociais }\end{array}$ & $\begin{array}{ll}\text { - } & \text { Orientações da hierarquia } \\
\text { - } & \text { Cooperação com os colegas } \\
\text { - } & \text { Informações para os usuários }\end{array}$ & $\begin{array}{c}\text { "Nunca consigo achar o meu chefe } \\
\text { para problemas rápidos" }\end{array}$ \\
\hline Perturbação & $\begin{array}{l}\text { - } \quad \text { Interrupções no processo de trabalho } \\
\text { - } \quad \text { Falta de cordialidade dos usuários } \\
\text { - } \quad \text { Panes no funcionamento da informática }\end{array}$ & $\begin{array}{l}\text { "Sempre ocorrem interrupções. } \\
\text { A gente não tem privacidade." }\end{array}$ \\
\hline Incerteza & $\begin{array}{ll}\text { - } & \text { Informações incompletas dos usuários } \\
\text { - } & \text { Legislação ambígua } \\
\text { - } & \text { Funcionamento do sistema }\end{array}$ & $\begin{array}{c}\text { “Ninguém pediu opinião a respeito da concepção } \\
\text { (do sistema), acho que deveriam ter perguntado } \\
\text { para entender o que a gente faz.” }\end{array}$ \\
\hline
\end{tabular}


texto de trabalho singular, cuja interação de diferentes variáveis aumenta o esforço de tratamento das informações. Assim, a construção de habilidades cognitivas é centrada na abstração (decodificar os sentidos das situações e planejar as ações) com base na experiência e nas informações disponíveis no campo perceptual.

Nesse sentido, os atendentes desenvolvem estratégias de regulação que visam atenuar o custo humano do trabalho que se caracterizam pelas habilidades de: diagnóstico das demandas; resoluções de problemas; gestão do tempo em função das prioridades, da comunicação e da cooperação intra e inter-equipes.

\section{Custo psíquico da atividade de atendimento ao público: indicadores de vivências de prazer-sofrimento}

Os resultados obtidos na Escala de Prazer-Sofrimento no Trabalho são apresentados na Tabela 3, e indicam a média total da amostra nos três fatores do instrumento. A diferença entre as médias nos três fatores é significativa, conforme resultados do teste " $\mathrm{t}$ " de comparação de médias entre grupos de diferentes variáveis, tendo apresentado níveis de significância de $\mathrm{p} \leq 0,05$. Considerando que a EPST é uma escala de cinco pontos, apresentando um ponto médio em três, os resultados diferenciam-se para os fatores do prazer (ambos abaixo da média, 2,3 para valorização e 2,6 para reconhecimento) e para o fator desgaste do sofrimento que se encontra acima do ponto médio (com média de 4,5).

Os resultados dessas análises indicam que existe um predomínio da vivência de sofrimento no serviço de atendimento ao público na organização estudada, e o prazer é vivenciado moderadamente pela proximidade do resultado dos fatores valorização e reconhecimento com o ponto médio da escala, significando que ambas existem para os trabalhadores, só que em níveis diferentes. Isso demonstra que as situações de prazer-sofrimento não são excludentes, ainda que para este grupo de trabalhadores predomine o sofrimento.

Os resultados em relação ao sofrimento indicam a presença do desgaste no trabalho. Os trabalhadores que sentem desgaste estão submetidos a atividades cansativas, desagradáveis, repetitivas, com mais sobrecarga, o que gera frustrações, desânimo, insatisfação. Também, significa pessoas submetidas a sistemas injustos de avaliação de desempenho, bem como a injustiças ligadas ao exercício do poder.

A vivência moderada de valorização e reconhecimento indica que os funcionários não estabelecem, de forma satisfatória, relações significativas com sua atividade, colegas e chefias, implicando que o contexto oferecido não apresenta condições necessárias para o trabalho ser fonte de prazer, predominando o sofrimento.

Não sentir valorização no trabalho significa que o sujeito não considera seu trabalho importante por si mesmo, para a empresa e para a sociedade, indicando assim, um reforço negativo na auto-imagem, que está relacionada ao orgulho pela atividade desempenhada, à realização profissional, ao sentir-se útil e produtivo, tendo espaço mais vivências de sofrimento do que de prazer.

$\mathrm{O}$ fato do reconhecimento aparecer um pouco abaixo da média pode significar que as relações socioprofissionais precisam ser melhoradas. Parecem existir problemas em relação à boa convivência com as chefias e os colegas, bem como relacionados ao espaço para construir um coletivo de trabalho no qual estão presentes as margens de liberdade para ajustar suas necessidades à tarefa.

Os resultados demonstram que o sofrimento se articula às imposições das condições externas às situações de trabalho impostas aos funcionários, expressas nos modos de organização do trabalho em termos das características da atividade. Isso significa que, para esse grupo, que vivencia pouco prazer, o trabalho não é lugar de realização, de identidade, valorização e reconhecimento, sendo necessário o desenvolvimento de determinadas condições que favoreçam a busca do prazer na direção de manter o seu equilíbrio psíquico.

A partir desses resultados, pode-se inferir que as situações de trabalho do grupo pesquisado são críticas e geradoras de vivências de sofrimento. Por essa razão, deve haver uma preocupação com os aspectos medidos pelo fator

Tabela 3.

Médias e desvio-padrão da amostra para os fatores valorização, desgaste e reconhecimento $(N=64)$

\begin{tabular}{ccc}
\hline Fatores & Médias & Desvio padrão \\
\hline Valorização & 2,39 & 0,83 \\
Reconhecimento & 2,67 & 0,73 \\
Desgaste & 4,50 & 10,31 \\
\hline
\end{tabular}


desgate (exemplos, sobrecarga, cansaço, repetitividade das tarefas, tédio e injustiças na gestão de pessoal), para que o prazer possa ser maximizado com a implantação de transformações que visem oportunizar a valorização e o reconhecimento no trabalho.

De um ponto de vista dinâmico, pode-se hipotetizar que o sofrimento vivenciado está sendo enfrentado com estratégias defensivas e criativas. As estratégias defensivas pressupõem a negação do sofrimento e a ausência de prazer. Como existe uma vivência moderada de prazer e o sofrimento está sendo revelado, é possível que esses trabalhadores estejam utilizando mais estratégias criativas, as quais visam transformar a realidade que gera o sofrimento, o que se reflete na não negação de algum tipo de sofrimento.

Essas hipóteses sugerem que esse grupo está submetido a modos de organização do trabalho que favorecem mais o sofrimento do que o prazer, ou ainda, a modos que não permitem a negociação entre sujeito e realidade de trabalho, o que oferece espaço para o sofrimento, mesmo que possa ser enfrentado, considerando-se a vivência moderada de prazer, que pode estar indicando o uso de estratégias criativas.

Em relação à análise da atividade levanta-se a hipótese de que o predomínio do sofrimento está relacionado com: a) as condições físicas, materiais e instrumentais de trabalho (setting de atendimento) como fatores dificultadores do processo; b) a carga de trabalho, que predominantemente é cognitiva, implicando um custo maior tendo em vista os elementos de complexidade que levam os atendentes a construir estratégias para garantir a eficiência e a eficácia do trabalho e assegurar o bem-estar.

A construção dessa estratégia articula-se ao uso da criatividade para enfrentar o sofrimento, significando assim, que apesar da predominância do sofrimento na função de atendimento ao público, os sujeitos buscam a redução do custo psíquico no trabalho, não convivendo com o sofrimento e, possivelmente, buscando estratégias para desenvolver o prazer, tendo em vista ser este um dos elementos para a sua estruturação psíquica. Isso não desconsidera as transformações que devem ser realizadas no contexto de trabalho para minimizar ou eliminar o sofrer, ajudando o trabalhador a restabelecer sua economia psíquica e alcançar maiores oportunidades para o seu bem-estar e saúde.

\section{Conclusão}

Os resultados do estudo evidenciam que a inter-relação entre a atividade de atendimento ao público e o bem-estar psíquico dos sujeitos são faces de uma mesma moeda. Os dados empíricos, provenientes das abordagens em ergonomia e em psicodinâmica, apontam um cenário inquietante na instituição estudada.
O enfoque da ergonomia mostra que a atividade de atendimento ao público se caracteriza por três aspectos interdependentes: (a) a execução dos serviços é centrada em um ritual quotidiano de tratamento rotineiro de informações, exigindo dos atendentes um trabalho mental intenso (identificação da demanda do usuário, busca, registro e transmissão de informações); (b) as condições ambientais, materiais e instrumentais de trabalho, disponibilizadas pela instituição no setting de atendimento, constituem variáveis limitadoras que dificultam as atividades dos sujeitos e reduzem a sua margem de manobra para que possam gerir as exigências do serviço; (c) a multiplicidade e a interação dos fatores de complexidade, constatados no trabalho, aumentam, sobretudo, as exigências cognitivas e psíquicas da atividade de atendimento, agregando dificuldades aos atendentes para a construção de suas estratégias de regulação.

O enfoque da psicodinâmica do trabalho mostra que a predominância das vivências de sofrimento estão associadas tanto às condições nas quais as atividades são realizadas, quanto às relações socioprofissionais. Esse resultado indica um alerta no sentido de serem desenvolvidas mudanças organizacionais para redução ou minimização dos fatores que causam cansaço, desânimo e descontentamento com o trabalho. Vale ressaltar, ainda, que a vivência moderada de prazer pode indicar um ponto positivo para a neutralização do sofrimento, sendo necessário para isso identificar os fatores geradores de prazer.

A escala de prazer-sofrimento teve papel epidemiológico. Permitiu uma descrição da situação geral do setor sob o ponto de vista da maioria dos seus membros. São importantes no sentido de mostrar a direção em que o fenômeno acontece no setor estudado, naquele momento e contexto organizacional, tendo sido de grande valia seus resultados para subsidiar e corroborar os dados provenientes das entrevistas e das observações.

O uso da escala justifica-se no nosso interesse de ter uma descrição da situação dos trabalhadores em dado momento. É saudável para o campo de investigação científica nas organizações e trabalho o uso de técnicas mistas de coleta de dados. Consideramos que do ponto de vista epistemológico, o fato de se usarem escalas de atitude para medir conceitos ditos subjetivos - até porque qualquer fenômeno estudado a partir da percepção é por si só subjetivo não significa necessariamente uma visão positivista do conhecimento. O que define o aspecto epistemológico é a construção do conhecimento a partir do dado empírico e não o dado em si. Nesse sentido, o uso de escalas para medir o prazer-sofrimento fornece indicadores para se ter acesso a uma situação que extrapola o dado, que se configura num conjunto de relações, na maioria das vezes dialética, que permite a interpretação e o avanço do conhecimento ao con- 
frontar dados quantitativos e qualitativos, não sendo negligenciados para isso, os pressupostos da psicodinâmica do trabalho, e possibilitando o diálogo com outras disciplinas, no caso a ergonomia.

O exame da inter-relação da ergonomia e da psicodinâmica nesse estudo possibilitou estabelecer um diálogo enriquecedor entre as duas disciplinas, permitindo identificar, ao mesmo tempo, as contribuições e os limites da abordagem interdisciplinar no estudo da temática.

Os dados da análise ergonômica mostram o contexto sociotécnico e a interação das principais variáveis que marcam as atividades dos sujeitos no serviço de atendimento ao público, em particular, os elementos críticos das situações que aumentam a carga de trabalho dos atendentes e dificultam a estruturação de suas estratégias de regulação. Nesse sentido, os dados constróem um cenário característico para o setor pesquisado no qual se inscrevem os resultados das vivências de prazer-sofrimento, obtidos pela abordagem da psicodinâmica. Tal cenário apresenta, sobretudo, elementos empíricos das situações de atendimento para se compreender a predominância das vivências de sofrimento entre os sujeitos, conforme constatado com a aplicação da EPST.

Todavia, essa investigação interdisciplinar exploratória não autoriza construir um quadro explicativo mais conclusivo, em termos de se estabelecer uma correlação inequívoca entre o trabalho real e as vivências de sofrimento constatadas. Globalmente, os dados da ergonomia agregam sentido aos resultados da psicodinâmica, tornam mais compreensíveis os achados da EPST, mas não permitem afirmações categóricas sobre a inter-relação atividade de atendimento e sofrimento no trabalho. Pontualmente, um dos limites do estudo é a carência de dados específicos e mais aprofundados relativos à interação social com os usuários, que possibilitariam mapear melhor essa importante dimensão da carga psíquica de trabalho.

Os resultados abrem novas perspectivas para intensificar o diálogo interdisciplinar, esboçado no presente estudo. Ele possibilitou, principalmente, propor novas questões: (a) Qual é a importância das situações críticas de trabalho, que conduzem às "falências" de estratégias de regulação, na gênese das vivências de sofrimento psíquico dos sujeitos? (b) Como construir um design metodológico que incorpore de forma interativa os pressupostos teóricos das duas disciplinas no processo de investigação? Fica, portanto, o desafio de futuras investigações empíricas sob as diferentes perspectivas teóricas, de forma a avançar no entendimento tanto dos processos de adoecimento, quanto do desenvolvimento da saúde no contexto de trabalho.

\section{Referências}

Bardin, L. (1974). Análise de conteúdo. Lisboa: Edições 70.
Brito, J. C. (1991). Procurando compreender os conceitos de carga, trabalho e risco (tecnológico). Revista Brasileira de Saúde Ocupacional, 19(72), 38-39.

Daniellou, F. (1984). Concepção de situações de trabalho e saúde. Paris: CNAM.

Dejours, C. (1987). A loucura do trabalho: estudo de psicopatologia do trabalho. São Paulo: Cortez.

Dejours, C. (1993). Travail: usure mental (v. 1). Paris: Bayard.

Dejours, C. (1994). Psicodinâmica do trabalho: contribuições da escola dejouriana à análise da relação prazer, sofrimento e trabalho. São Paulo: Atlas.

Dejours, C. (1995). Que sais-je? Le facteur humain. Paris: PUF.

Dejours, C. (1997). Conférence d' introduction. In Acts: Colloque International de Psycodynamique et Psychopathologie du Travail (Tome II., p. 4). Paris: Conservatorie Nátional des Arts et Métiérs.

Dejours, C. (1998). Souffrance en France: la banalisation de l' injustice sociale. Paris: Éditions du Sevil.

Falzon, P., \& Lapeyrière, S. (1998). L'usager et l'opérateur: Ergonomie et relations de service. Le Travail Humain, 61(1), 69-90.

Ferreira, M. C. (no prelo). Atividade, categoria central na conceituação de trabalho em ergonomia. Alethéia.

Ferreira, M. C., Araujo, F. B. O., \& Araujo, D. L. M. (1998). A teoria e a prática no trabalho do caixa de supermercado. XXVIII Reunião Anual de Psicologia - Resumos, Ribeirão Preto, Brasil, p.143.

Ferreira, M. C., Carvalho, R. S., \& Sarmet, M. M. (1999). Ergonomia do serviço de atendimento ao público: um estudo de caso. [CD-ROM]. IX Congresso da Associação Brasileira de Ergonomia, Resumos, Salvador, Brasil.

Ferreira, L. L., \& Marcelin, J. (1983). Orientações atuais da metodologia ergonômica na França. Revista Brasileira de Saúde Ocupacional, 11(41), 65.

Freire, O. N., \& Ferreira, M. C. (2000). "A empresa não perde nada, só a gente": Carga de trabalho do frentista e a prática da rotatividade sistemática. Trabalho apresentado no II Seminário Nacional de Psicologia e Direitos Humanos, Conselho Federal de Psicologia, Brasília, DF.

Gonçalves, R. M., \& Ferreira, M. C. (1999). Serviço de atendimento ao público e home-pages governamentais. [CD-ROM]. IX Congresso da Associação Brasileira de Ergonomia, Resumos, Salvador, BA.

Hubault, A. (1995). A quoi sert l'analyse de l'activité en ergonomie. Performances Humaines \& Techniques, (Hors Série), 79-85.

Jayet, C. (1994). Psychodynamique du travail au quotidien. Paris: AleXitére.

Laurell, A. C., \& Noriega, M. (1989). Processo de produção e saúde: trabalho e desgaste operário. São Paulo: Hucitec.

Laville, A. (1983). L'ergonomie. Paris: PUF.

Laville, A., Teiger, C., \& Daniellou, F. (1989). Ficção e realidade do trabalho operário. Revista Brasileira de Saúde Ocupacional, 17(56), 7-13.

Leplat, J. (1996). Quelques aspects de la complexité en ergonomie. In F. Daniellou (Org), L'ergonomie en quête de ses principes (pp. 57-76). Toulouse: Octarès.

Leplat, J., \& Hoc, J-M. (1983). Tâche et activité dans l'analyse psychologique des situations. In J. Leplat (Org.), L'analyse du travail en psychologie ergnomique (Recueil de Textes) (Tome 1, pp. 47-59). Toulouse: Octarès.

Mendes, A. M. (1995). Os novos paradigmas de organização do trabalho: implicações para saúde mental do trabalhador. Revista Brasileira de Saúde Ocupacional. 85/86 (23), 55-60.

Mendes, A. M. (1996). Comportamento defensivo: uma estratégia para suportar o sofrimento no trabalho. Revista de Psicologia, 13/14 (1/2), 27-32. 
Mendes, A. M. (1999). Valores e vivências de prazer-sofrimento no contexto organizacional. Tese de doutorado não-publicada. Universidade de Brasília, Brasília.

Mendes, A. M., \& Abrahão, J. I. (1996). A influência da organização do trabalho nas vivências de prazer-sofrimento do trabalhador: uma abordagem psicodinâmica. Psicologia: Teoria e Pesquisa, 26(2), 179-184.

Mendes, A. M., \& Linhares, N. J. (1996). A prática do enfermeiro com pacientes da UTI: uma abordagem psicodinâmica. Revista Brasileira de Enfermagem, 42(2), 267-280.

Moraes, A., \& Mon'Alvão, C. (1998). Ergonomia, conceitos e aplicações. Rio de Janeiro: $2 \mathrm{AB}$.

Santos, V., Chaves, J. M. M. F., Pavão, J. C. M., \& Bijos, P. (1994). Projeto ergonômico de centrais de atendimento. Rio de Janeiro: Ergon Projetos.

Schwartz, Y. (1992). Sur le concept de travail. Actes du Colloque Interdisciplinaire Travail: Recherche et Prospective - Thème Trans- versal $n^{o} 1$ - Concept de Travail (pp. 101-110). Lyon: CNRS, PIRTTEM, ENS

Teiger, C. (1992). Le travail, cet obscur objet de l'ergonomie. In Actes du Colloque Interdisciplinaire Travail: Recherche et Prospective - Thème Transversal $n^{o} 1$ - Concept de Travail (pp. 111-126). Lyon: CNRS, PIRTTEM, ENS.

Terssac, G. (1995). Le travail organisé: faut-il repenser le travail? Actes du XXX Congrès de la Société d'Ergonomie de Langue Française, Biarritz, França, 5-9.

Weill-Fassina, A. (1990). L'analyse des aspects cognitifs du travail. In M. Dadoy, C. Henry, B. Hillau, G. de Tersac, J.- F. Troussier \& A. WeillFassina (Orgs.), Les analyses du travail enjeux et formes (pp. 193198). Paris: CEREQ.

Weill-Fassina, A., Dubois, D., \& Rabardel, P. (1993). Représentations pour l'action. Toulouse: Octares.

Wisner, A. (1994). A inteligência no trabalho: textos selecionados. São Paulo: Fundacentro.

\section{Nota}

${ }^{1}$ Este artigo tem origem em um projeto de intervenção intitulado "Bem-estar dos funcionários e satisfação dos usuários no serviço de atendimento ao público: diagnóstico e recomendações”, desenvolvido pelo Laboratório de Ergonomia da Universidade de Brasília - UnB.

Mário César Ferreira, doutor em Ergonomia pela Ecole Pratique des Hautes Etudes (EPHE), Paris, França, bolsista de Produtividade em Pesquisa do CNPq, é Professor do Departamento de Psicologia Social e do Trabalho da Universidade de Brasília.

Ana Magnólia Mendes, doutora em Psicologia pela Universidade de Brasília, DF, bolsista de Produtividade em Pesquisa do CNPq, é Professora do Departamento de Psicologia Social e do Trabalho da Universidade de Brasília.

Endereço para correspondência: Universidade de Brasília (UnB), Dep. de Psicologia Social e do Trabalho, Instituto de Psicologia, Asa Norte, Campus Darci Ribeiro, 70.910 - 900, Brasília, DF. Tel.: (61) 307.26 25, ramal 224; Fax: (61) 347.77 46. E-mail: mcesar@unb.br (MCF) e anamag@yawl.com.br(AMM). 